\title{
Physicochemical Studies of the Destructive Alkali- Aggregate Reaction in Concrete
}

\author{
Robert G. Pike and Donald Hubbard
}

\begin{abstract}
In a further study of the alkali-aggregate reaction in high-alkali cements, 11 reactive and nonreactive experimental aggregates were examined by several procedures. On comparing the results of each method with the standard expansion-bar test, it appears that each property studied has some bearing on the expansion characteristics of each aggregate. For example: (1) The chemical durability as determined by the interferometer procedure was poor for the aggregates that showed excessive expansion, but not all aggregates that are shown to be chemically reactive by this procedure will cause expansion, (2) all aggregates are sufficiently hygroscopic to attract the water necessary for the reaction if other properties are also favorable, (3) surface electrical-resistance measurements confirm the hygroscopicity determinations; however, free ions in glasses may have considerably more effect on the surface resistance of certain glasses than do their hygroscopic properties, and (4) the uneven distribution of migratable ions between the aggregate surface and the outer phase offers a mechanism for the osmotic swelling of individual aggregate grains, with accompanying expansion in concrete members.
\end{abstract}

\section{Introduction}

In a previous publication [1] ${ }^{1}$ concerning the mechanism of the destructive expansion of concrete structures caused by opaline and glassy silicate types of materials when used with high-alkali cements $[2,3,4]$ there were included some data on the chemical durability of a few natural and synthetic aggregates. Those results, obtained with an interferometric procedure under controlled exposures of time, temperature, and $p \mathrm{H}$, illustrated surface alterations of the aggregate materials during the incipient stages of attack. In light of the varied and unexpected dimensional changes found for various reactive and nonreactive aggregates, it became apparent that much remained to be learned about the chemical and physical nature of these and kindred materials before any completely acceptable picture of the destructive alkali-aggregate reaction could be formulated.

The present investigation was undertaken to gain further insight into the physicochemical principles operating in the alkali-aggregate reaction by extending the previous work on chemical durability to a broader range of aggregate materials. Further, in order to obtain a more comprehensive picture of the nature of these materials, their relative hygroscopicities, heterogeneous equilibria, electrical surface resistance, and reactivity in expansion bars were studied.

\section{Experimental Techniques and Results}

\subsection{Techniques}

For the sake of clarity, the techniques for each of the procedures are outlined briefly or covered by references in the sections where the results for each of the respective methods are presented and discussed.

\footnotetext{
Figures in brackets indicate the literature references at the end of this paper.
}

\subsection{Expansion Bars}

The expansion of standard mortar test bars $[5,6]^{2}$ brought about by 11 different aggregates when used in a high-alkali cement is shown in figure 1. The three forms of silica, viz, quartz (crystalline

2 The expansion bars were prepared and measured according to the procedure of Mielenz and Witts [5]. A water to cement to standard Ottawa sand ratio of 0.4 to 1 to 2 was used, and the bars were then stored over water at $100^{\circ} \mathrm{F}$, as described in a previous paper [1]. Six percent of Ottawa sand was replaced by the aggregate under test, using the size fraction passing a No. 50 and retained on a No. 100 U. S. Standard Sieve. This size gave maximum expansion with Pyrex, and 6 percent seemed a fair compromise between the expansion caused by the addition of 8 percent of Pyrex, as reported previously [1], and that caused by lower percentages of opal, as reported by other investigators [4, 8]. An analysis of the cement used is given in table 1 . However, it should be kept in mind that the curves in figure 1 would be altered if the test conditions, such as percentage [4] or size [8] of aggregate, temperature of storage [9], and percentage of alkali [10], were changed.

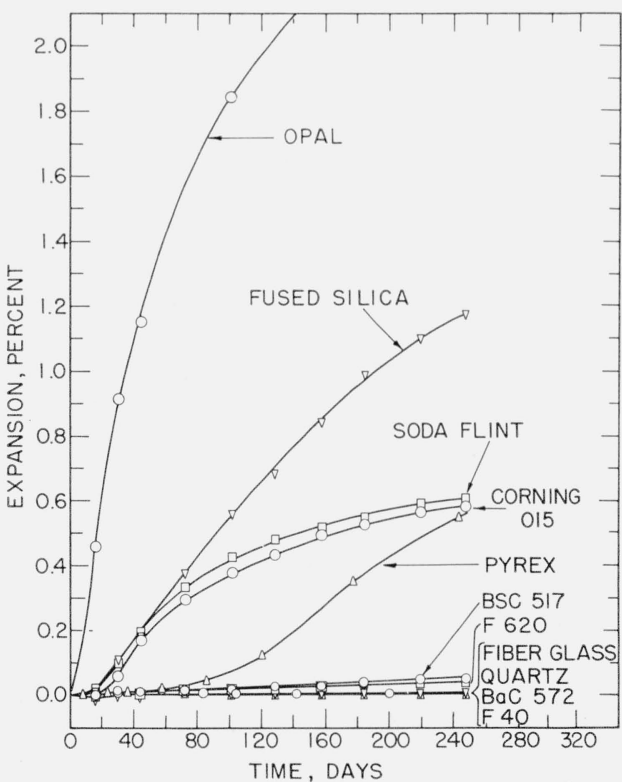

FIgURE 1. Expansion of mortar bars aged over water at $100^{\circ} \mathrm{F}$, made from high-alkali cement, and with 6 percent of the standard Ottawa sand replaced by various reactive and nonreactive aggregates. 
$\mathrm{SiO}_{2}$ ), fused $\mathrm{SiO}_{2}$ (glass), and opal (hydrous $\mathrm{SiO}_{2}$ ), form an interesting series, ranging in activity from quartz with no abnormal expansion of the bars in 8 months, to opal with approximately 2 percent of expansion in 4 months, followed by mechanical failure of the specimens. Fused $\mathrm{SiO}_{2}$ occupies an intermediate position, with an expansion far in excess of permissible tolerance [5]. Other aggregates besides quartz causing no appreciable expansion are $\mathrm{F} 40, \mathrm{BaC} 572$, and fiber glass type E. Pyrex 7740 , the glass adopted as a standard reactive aggregate [6], is included for comparison.

The induction period, which appears in the curves for the reactive aggregates, can be partially attributed to the shrinkage that takes place during the early stages of the setting of cements. However, the great difference in the induction periods for different materials implies that the induction features are primarily characteristic of the individual aggregates. These composite characteristics are undoubtedly a function of the chemical durability and other chemical and physical properties of the materials and the storage environment.

\subsection{Chemical Durability ${ }^{3}$}

The varied chemical durabilities over an extended $p \mathrm{H}$ range, characteristic of the 11 aggregates evaluated in figure 1 , are shown in figures $2,3,4$, and 5 .

The chemical-durability curves for the three forms of $\mathrm{SiO}_{2}$ (quartz, fused $\mathrm{SiO}_{2}$, and opal) are shown in figure 2 . These three forms of silica have distinctive individual durability characteristics, with quartz showing no detectable alteration between $p \mathrm{H} 2$ and $p \mathrm{H}$ 11.8. Over the same range, fused silica shows surface alteration (attack) only at alkalinities above $p \mathrm{H} 10$, whereas opal exhibits dimensional changes over the entire $p \mathrm{H}$ range, with liberal swelling in the acid buffers and severe attack at $p \mathrm{H}$ 11.8. The relative order for destructive swelling of mortar bars by these three forms of silica is the same as for their relative chemical durabilities, with quartz the least and opal the most reactive.

In figure 3 are grouped the silicate aggregates that exhibit pronounced swelling over the acid range and well into the alkaline region, similar to opal. These three greatly dissimilar silicates (table 1), having the common characteristic of swelling, also cause conspicuous destructive expansion of mortar bars, as shown in figure 1. Continuing, in figure 4 are presented the glassy aggregates that showed unusual attack near neutrality by the buffers between $p \mathrm{H} 4$ and $p \mathrm{H} 10$, in contrast to the aggregates shown in figure 3, with extensive swelling over the same $p \mathrm{H}$ range. A glance at figure 1 reveals a pronounced difference for these groups in the expansion-bar test. For example, of those with the attack near $p \mathrm{H} 7$, one ( $\mathrm{BaC} 572)$ shows no destructive expansion, and

${ }^{3}$ The chemical durability of the various aggregates was determined by an interferometer procedure that has been particularly useful in the study of the chemical durability of optical glasses, voltage anomalies of the glass electrode, and in practical applications in various other fields [11, 12]. The procedure consists in observing the surface alteration of the specimen after exposure to Britton-Robinson universal buffer mixtures [13] for $6 \mathrm{hr}$ at $80^{\circ} \mathrm{C}$.

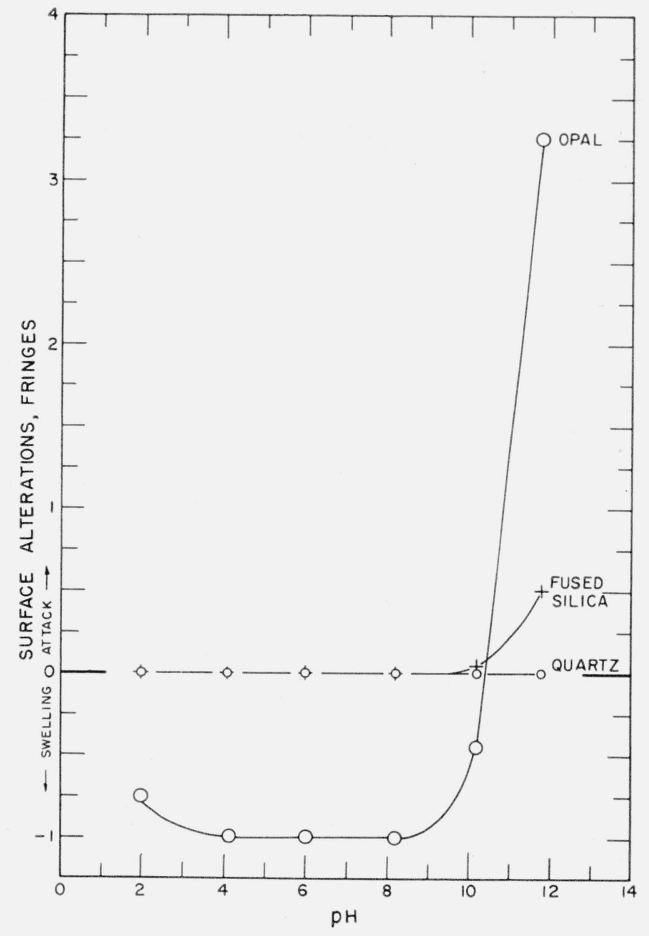

FIGURE 2. Chemical durability (surface alteration) of three forms of silica.

Exposure $6 \mathrm{hr}$ at $80^{\circ} \mathrm{C}$.

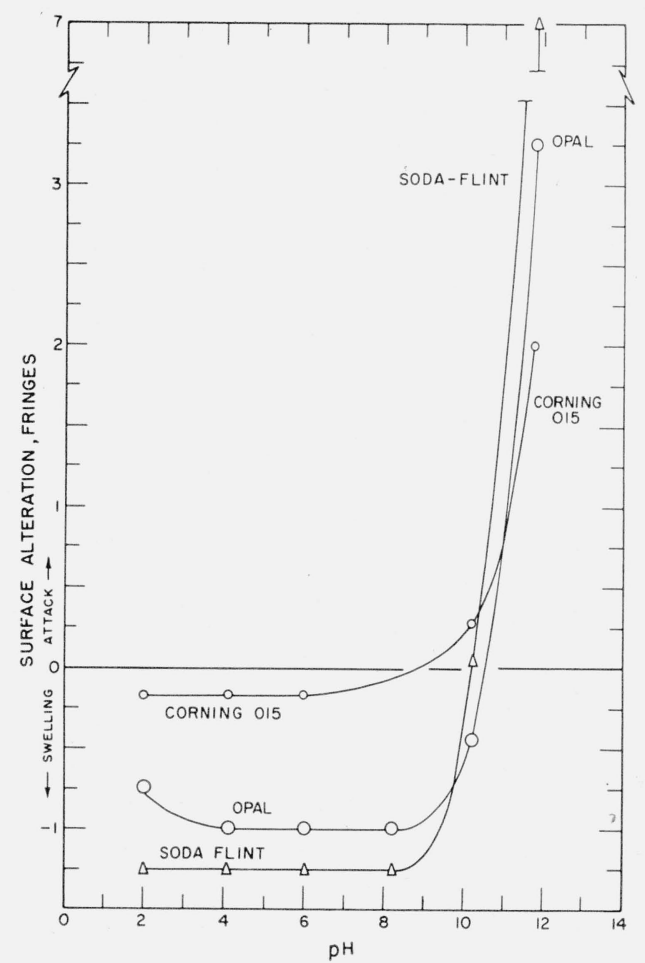

FIGURE 3. Chemical durability (surface alteration) of three aggregates that exhibit swelling in the acid range.

Exposure $6 \mathrm{hr}$ at $80^{\circ} \mathrm{C}$. 
TABLE 1. Chemical compositions

\begin{tabular}{|c|c|c|c|c|c|c|c|c|c|c|c|}
\hline Oxides & 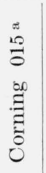 & 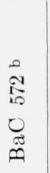 & $\begin{array}{l}\stackrel{2}{10} \\
\frac{10}{10} \\
0 \\
0 \\
\infty\end{array}$ & ำ & 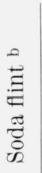 & 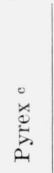 & 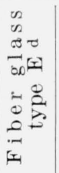 & $\stackrel{f}{P}$ & $\frac{\stackrel{\square}{\varpi ٌ}}{0}$ & $\frac{\tilde{m}}{\tilde{\sigma}}$ & 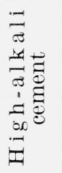 \\
\hline $\mathrm{Na}_{2} \mathrm{O}$ & 22 & 0.4 & 8.4 & 3.6 & 20 & 3.8 & & & & & 1. 10 \\
\hline $\mathrm{K}_{2} \mathrm{O}$ & $\ldots$ & 7.7 & 11.8 & 5. 2 & & 0.4 & & & & & 0.09 \\
\hline $\mathrm{CaO}$ & 6 & & & & & & 16. 0 & & & & 63.3 \\
\hline $\mathrm{BaO}$ & .... & 30.8 & & & & & $\ldots$ & 30 & & & \\
\hline $\mathrm{PbO}$ & & & & 45.1 & 20 & & & $\ldots$ & & & $\ldots-\ldots$ \\
\hline $\mathrm{ZnO}$ & & 7. 2 & 0.5 & & & & & & & & \\
\hline $\mathrm{B}_{2} \mathrm{O}_{3-}$ & & 3. 6 & 12.4 & & & 12.9 & 9.5 & & $\ldots$ & & \\
\hline $\mathrm{As}_{2} \mathrm{O}_{3-}$ & & 0.2 & 0.5 & 0.5 & & & 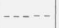 & & & & $\ldots$ \\
\hline $\begin{array}{l}\mathrm{Sb}_{2} \mathrm{O}_{3}- \\
\mathrm{SiO}_{2}\end{array}$ & 72 & $49^{\cdot} \cdot \frac{4}{7}$ & 66.4 & 456 & 60 & 80.5 & 55 & 50 & 9309 & 9038 & 216 \\
\hline & & & & & & 2. 2 & 14.5 & & 0.87 & 2.72 & 60 \\
\hline & & & & & & & & & $\begin{array}{r}0.08 \\
.11\end{array}$ & 0.54 & $\begin{array}{l}0.0 \\
2.5\end{array}$ \\
\hline $\mathrm{MgO}_{-}$ & & & & & & & 5.0 & & +11 & 0.01 & 1.9 \\
\hline $\mathrm{SO}_{3} \ldots$ & & & & & & $\ldots$ & $\ldots$. & & & & 2.3 \\
\hline $\mathrm{TiO}_{2} \ldots \ldots$ & & & & & & & & 20 & & & \\
\hline Ignition loss_- & & & & & & & & & 5. 40 & 5. 32 & 1. 1 \\
\hline Insoluble & & & & & & & & & & & - \\
\hline $\mathrm{HF}$ residue $\mathrm{g}_{\text {. }}$ & & & & & & & & & 1. 51 & 4. 30 & \\
\hline
\end{tabular}

a Composition from references [1,11]. b Compositions of batch material c Composition from C. J. Phillips, Glass, the miracle maker, p. 47. Pitman Publishing Corp. New York, N. Y. d Composition from reference [11]. e Selected clear pieces, used in all tests except expansion bars. ${ }_{\mathrm{f}} \mathrm{Run}$-of-mine grade, used in expansion bars. g The HF residue was fused and dissolved and $\mathrm{R}_{2} \mathrm{O}$ precipitated with $\mathrm{NH}_{4} \mathrm{OH}$ and ignited. The $\mathrm{Fe}_{2} \mathrm{O}_{3}$ was determined in the ignited precipitate and the remainder of the $\mathrm{R}_{2} \mathrm{O}_{3}$ assumed to be $\mathrm{Al}_{2} \mathrm{O}_{3}$.

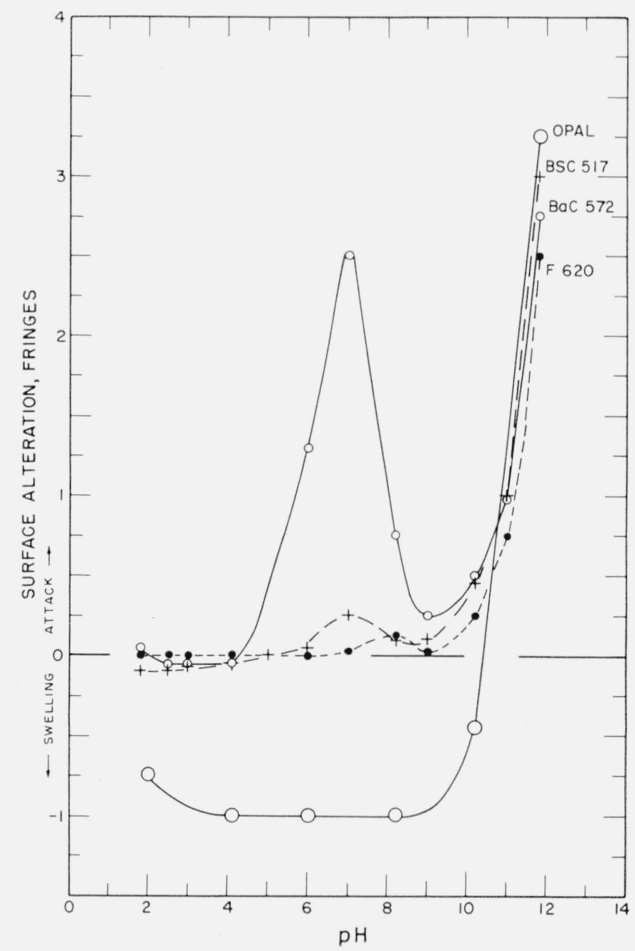

FIgURE 4. Chemical durability (surface alteration) of three aggregates (optical glasses) showing unusual attack near neutrality.

Data by Bernard R. Nebel. the other two (BSC 517 and F 620) much reduced or delayed action.

An additional group of experimental aggregates is given in figure 5 , in which the chemical durability of Pyrex 7740 glass, which serves as a standard reactive aggregate for testing high-alkali cements [6], is compared with F 40 and fiber glass (commercial type E). The latter two aggregates show attack in the acid region at $p \mathrm{H} 2$, but are dissimilar in their reaction in the alkaline range, with $\mathrm{F} 40$ being unaltered, whereas the fiber glass is severely attacked. These two aggregates, along with quartz and $\mathrm{BaC} 572$, showed no destructive expansion of the test mortar bars. As F 40 and quartz are chemically resistant to attack by the high-alkaline buffers, their acceptable behavior in the mortar-bar tests is to be expected. The behavior of $\mathrm{BaC} 572$ and the fiberglass aggregates, with their poor chemical durability in the alkaline range, seems to be anomalous. However, these two exceptions furnish the most interesting and probably the most useful data of the entire series. For example, cross sections of the expansion bars reveal that $\mathrm{BaC} 572$ and fiber-glass aggregates had not been attacked by the highalkaline conditions [14] existing in the hydrated high-alkali cement. Thus, the inhibiting effect of saturated $\mathrm{Ca}(\mathrm{OH})_{2}[15]$ from the cement, and certain individual constituents of the aggregates, such as barium and magnesium oxides, must be examined in future experiments.

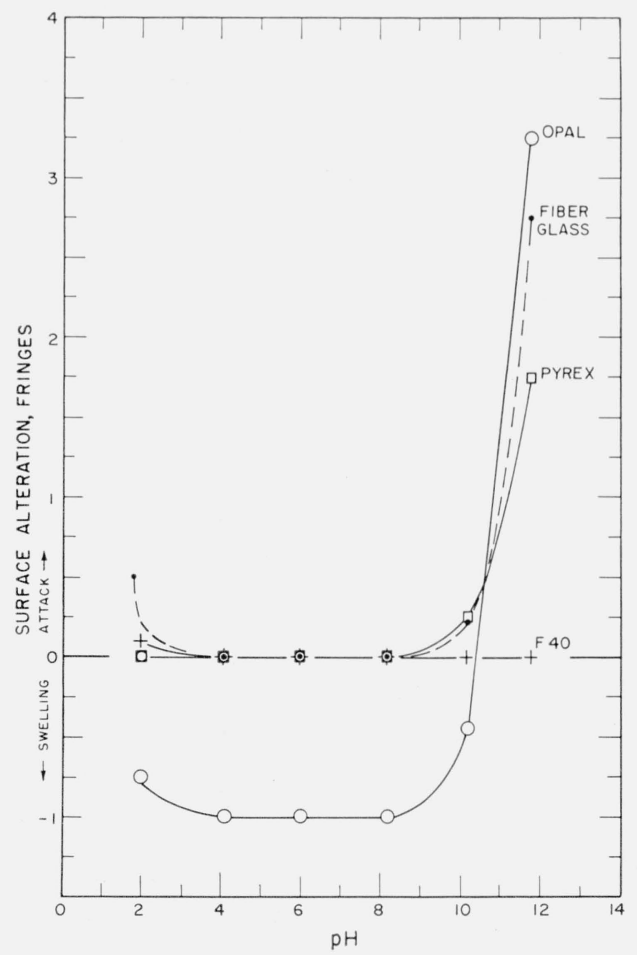

Figure 5. Chemical durability of three special-purpose glasses. 


\subsection{Hygroscopicity ${ }^{4}$}

As the alkali-aggregate reaction cannot take place without the presence of water, and also because water is one of the chief constituents in the products resulting from the reactions, the relative hygroscopicities of the aggregate materials were determined. Figure 6 illustrates the results obtained for the 11 aggregates of figure 1 , after 1 and $2 \mathrm{hr}$ of exposure. Some of the groupings applicable to the chemical-durability data persist for the hygroscopicity in a supericial fashion. For example, the three forms of $\mathrm{SiO}_{2}$ fall in the order, opal, fused $\mathrm{SiO}_{2}$, and quartz, although the differentiation between fused $\mathrm{SiO}_{2}$ and quartz is not very pronounced. The three chemically dissimilar aggregates, opal, Corning 015, and soda flint, characterized by swelling in the acid range, are also the three most hygroscopic materials of figure 6 . Likewise, 6 of the 7 aggregates that caused unacceptable destructive expansion of mortar bars are found to be the most hygroscopic of the 11 materials tested, fused silica being the only destructive aggregate that does not conform. $\mathrm{BaC} 572$, fiber glass, quartz, and $\mathrm{F} 40$, the 4 nondestructive aggregates, are among the 5 least hygroscopic materials. The fact that fused $\mathrm{SiO}_{2}$ constitutes such a glaring exception once again furnishes the most interesting data of the series and needs further study.

4 The procedure for determining hygroscopicity was that reported in a previous publication [1], which consists in determining the change in weight of samples (water sorbed [16], ground to pass a No 140 U S. Standard Sieve) when exposed to the high humidity maintained by a saturated aqueous solution of $\mathrm{CaSO}_{4} \cdot 2 \mathrm{H}_{2} \mathrm{O}$

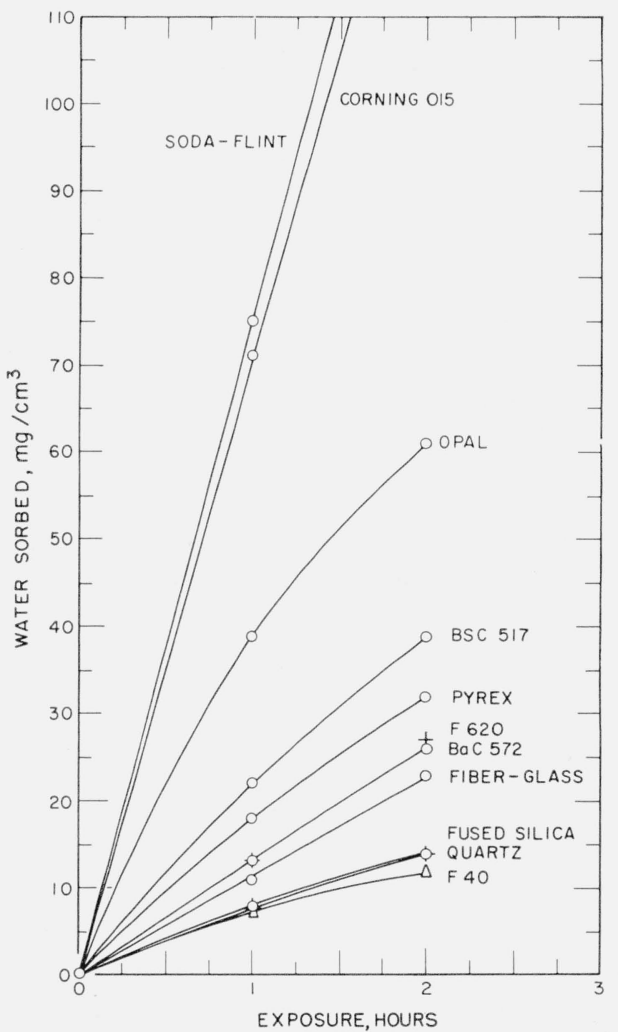

FIGURE 6. Hygroscopicity of the 11 reactive and nonreactive aggregates shown in figure 1.

\subsection{Heterogeneous Equilibria}

The uneven distribution of migratable ions, as shown in figure 7, using excess $\mathrm{Ag}\left(\mathrm{NH}_{3}\right)_{2}{ }^{+}$as the indicator, reveals that the aggregate materials studied possess a negative nonmigratable ionic charge after leaching. Early inquiry into the destructive expansion of concrete structures caused by the presence of reactive aggregates, when used with high-alkali cement, revealed that osmotic forces were operative $[3,17]$. In addition to differentiating between aggregate materials, these data also demonstrate that the frameworks of these materials (primarily silicates) behave as negatively charged nonmigratable ions. This condition is favorable for initiating and accelerating reaction within the silicate framework. The increased sodium ion concentration within the silicate framework over that in the ambient phase would reduce the solubility of $\mathrm{Ca}(\mathrm{OH})_{2}$ so that it precipitates at the aggregate surface [14], inhibiting reaction there while the inner portion of the particle was being completely reacted and disintegrated as alkali silicates [1, fig. 14]. The destructive capacity of any aggregate would be partially determined by this heterogeneous equilibrative factor and by the chemical and physical nature of the reaction products.

The three forms of $\mathrm{SiO}_{2}$ fall in their usual order of reactive and destructive capacity, with opal occupying the least, and quartz the most favorable position of the series.

5 In the experiments on heterogeneous equilibria, the uneven distribution of the migratable ions $\mathrm{Ag}\left(\mathrm{NH}_{3}\right)_{2}+$ and $\mathrm{Br}$ - between the aggregate material and the ambient phase was determined by potentiometric titration of the excess $\mathrm{Ag}^{+}$ ions remaining with the aggregate or the excess $\mathrm{Br}^{-}$ions appearing in the ambient ions remaining with the aggregate or the excess $\mathrm{Br}-$ ions appearing in the ambient solution after the leached aggregate sample was treated with full-strength aqueous
$\mathrm{NH}_{4} \mathrm{OH}$ saturated with $\mathrm{AgBr}$. The procedure consisted in treating $10 \mathrm{~g}$ of aggre$\mathrm{NH}_{4} \mathrm{OH}$ saturated with $\mathrm{AgBr}$. The procedure consisted in treating $10 \mathrm{~g}$ of aggre-
gate material $(-50-,+140$-mesh particle size $)$ with $50 \mathrm{ml}$ of the $\mathrm{Ag}\left(\mathrm{NH}_{3}\right)_{2} \mathrm{Br}$ solution for 5 minutes, decanting and acidifying, followed by potentiometric titration, using $\mathrm{Ag}-\mathrm{AgBr}$ and glass electrodes as the indicator and reference electrode, respectively. Standardized solutions of $\mathrm{KBr}$ or $\mathrm{AgNO}_{3}$ (whichever the situation required) were used in the titration.

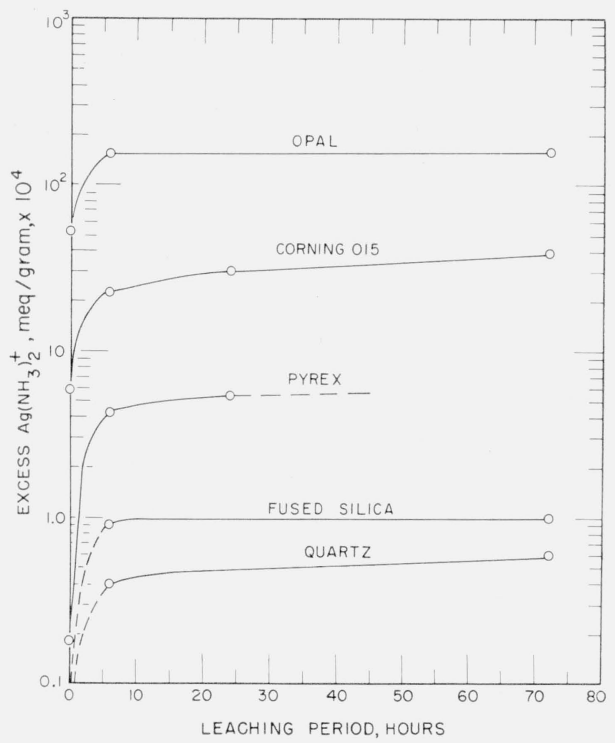

FIGURE 7. Uneven distribution of migratable ions expressed as milliequivalents per gram of sample across the aggregate solution interface, after various periods of leaching at $\mathrm{pH} 4.1$ at $80^{\circ} \mathrm{C}$, using $\mathrm{Ag}\left(\mathrm{NH}_{3}\right)_{2}+$ as the indicator ion. 


\subsection{Surface Resistance ${ }^{6}$}

Figure $8 \mathrm{~B}$ shows the surface electrical resistance obtained for the same five aggregates whose heterogeneous equilibrium characteristics are given in figure 7. The surface resistances for the three forms of silica constitute a consistent series comparable with the heterogeneous equilibrium data, but the positions of the opal and Corning 015 aggregates are reversed. They follow, instead, the order of their hygroscopicity characteristics in figure 6 . Thus, it appears that electrical surface-resistance measurements may give an indication of hygroscopicity. However, there are marked differences in the characteristics of the curves for these two types of data. The electrical-resistance data come to apparent acceptable equilibrium values for periods exceeding $2 \mathrm{hr}$, whereas the hygroscopicity curves (figs. 8A and 6) do not. In some cases, hygroscopicity values have continued to increase with the acquisition of water vapor until the weighing bottles have been filled to overflowing, as dictated by the lowered vapor pressure of aqueous solutions. On the other hand, electrical-resistance measurements give

${ }_{6}$ The surface-resistance data were obtained by measuring with an eight-decade logarithmic ohmmeter [18] the resistance of a cell (fig. 10) containing a measured volume of powdered sample $(-30,+50$ U. S. Standard Sieve) when the cell was placed in the grid circuit and exposed to a controlled relative humidity. This special meter was necessary because the usual d-c megohm bridge caused excessive polarization, and the readings by the available a-c meters were vitiated by the capacity of the cell.

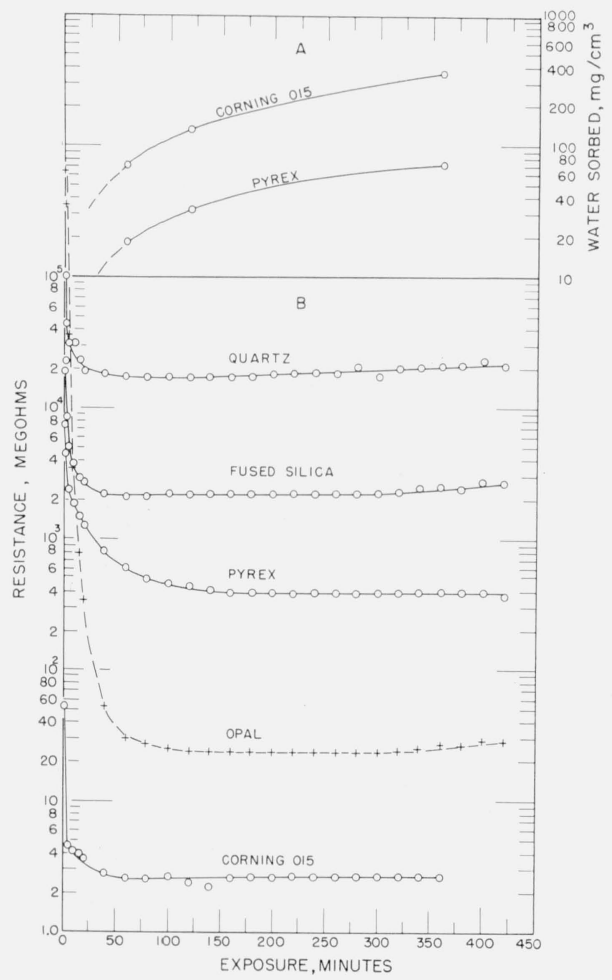

FIGURE 8. Electrical resistance and water sorption of several aggregates.

A, Typical hygroscopicity curves illustrating continued sorption of water with time of exposure; B, typical surface electrical resistance curves for five aggregates exposed to 98 percent relative humidity at flow rate of 0.5 liter per minute, illustrating an equilibrium state after $2 \mathrm{hr}$. constant values characteristic of the aggregate material. $^{7}$

Although the surface ohmic resistance and hygroscopicity of the aggregates might be expected to parallel each other, inspection of the results in figures 6 and 9 reveal reversals of position for several of the aggregates, and some of these even occupy different positions at different humidities. These latter reversals are undoubtedly determined by the nature of the hydrated and hydrolyzed reaction products following the sorption of moisture.

7 This constant resistance can be attained much more rapidly at faster flow rates through the resistance cell.

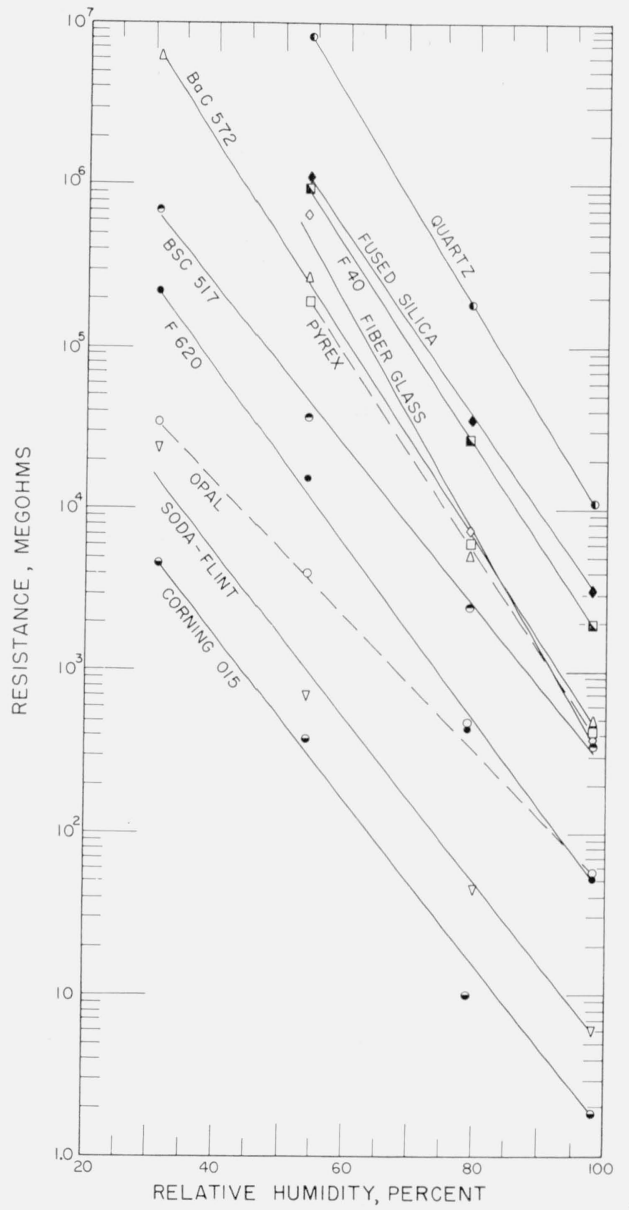

FIGURE 9. Surface electrical resistance of 11 reactive and nonreactive aggregates at various relative humidities.

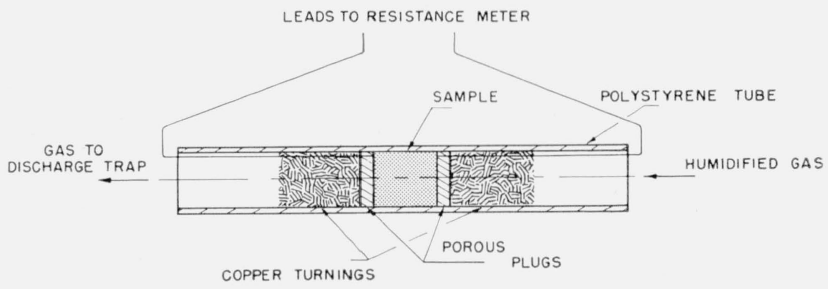

FIGURE 10. Diagram of the cell used in measuring the resistance of aggregate samples while being exposed to controlled relative humidities. 


\section{Conclusions}

Although the properties studied and the procedures used lead to a broader understanding of the aggregate materials and of the part played by various physicochemical principles operative in the destructive expansion of concrete structures, it is evident that no single property was determined that can be used as a serviceability criterion for all materials.

The authors thank Given W. Cleek and S. B. Garfinkel for their assistance in the progress of this investigation, the former for furnishing experimental aggregate materials of special and interesting properties and the latter for designing and assisting in building the eight-decade logarithmic ohmmeter.

\section{References}

[1] Robert G. Pike, Donald Hubbard, and Herbert Insley, Mechanism of alkali-aggregate reactions, Proc. Am. Concrete Inst. 52, 13 (1955).

[2] Thomas E. Stanton, Expansion of concrete through reaction between cement and aggregate, Proc. Am. Soc. Civil Engrs. 66, 1781-1811 (1940).

[3] W. C. Hansen, Studies relating to the mechanism by which the alkali-aggregate reaction produces expansion in concrete, Proc. Am. Concrete Inst. 40, 213-227 (1944).

[4] A. R. Alderman, A. J. Gaskin, R. H. Jones, and H. E. Vivian, Studies in cement aggregate reaction, Bulletins 229 and 256, Commonwealth Sci. and Ind. Research Organization, Australia (1947, 1950).

[5] Richard C. Mielenz and Leslie P. Witte, Tests used by Bureau of Reclamation for identifying reactive concrete aggregates, Am. Soc. Testing Materials, Proc. 48, 1071-1103 (1946).
[6] Federal Specification, SS-C-208b, Cement: PortlandPozzolan (1954).

[7] A. J. Gaskin, R. H. Jones, and H. E. Vivian, The reactivity of various forms of silica in relation to the expansion of mortar bars, Australian J. Appl. Sci. 6, 78 (1955).

[8] Donald O. Woolf, Reaction of aggregate with low-alkali cement, Public Roads 27, 50 (1952).

[9] H. E. Vivian, XVII: Some effects of temperature on mortar expansion, Australian J. Appl. Sci. 2, 114 (1951)

[10] C. E. S. Davis, XVIII: The effect of soda content and of cooling rate of Portland cement clinker on its reaction with opal in mortar, Australian J. Appl. Sci. 2, 123 (1951)

[11] Martin J. O'Leary and Donald Hubbard, Some properties of a glass used in paper manufacture, J. Research NBS 55, 1 (1955) RP2599.

[12] Robert G. Pike and Donald Hubbard, An interferometer procedure applied to the study of the chemical durability of silicates, enamels, and metals, J. Research NBS 50, 87 (1953) RP2394.

[13] H. T. S. Britton, Hydrogen ions I, 3d ed, p. 313 (D. van Nostrand Co., New York, N. Y., 1943).

[14] George Kalousek, C. H. Jumper, and J. J. Tregoning, Composition and physical properties of aqueous extracts from Portland cement clinker pastes containing added materials, J. Research NBS 30, 215 (1943) RP1530.

[15] George Verbeck and Charles Gramlich, Osmotic studies and hypothesis concerning alkali-aggregate reaction, Am. Soc. Testing Materials, Proc. 55, 1110 (1955).

[16] James W. McBain, The mechanism of the adsorption (sorption) of hydrogen on carbon, Phil. Mag. 18, 916 (1909); Z. physik. Chem. 68, 471 (1909).

[17] D. McConnell, R. C. Mielenz, W. Y. Holland, and K. T. Greene, Cement and aggregate reaction in concrete, Proc. Am. Concrete Inst. 44, 93 (1947).

[18] Samuel B. Garfinkel, An eight decade logarithmic ohmmeter, Instrument Soc. Am. J. 3, 54 (1956).

Washington, January 31, 1957. 